\title{
Psychological Intervention in Community-Based Treatment of Schizophrenia: a Systematic Narrative Review
}

\author{
Osi Kusuma Sari* \\ Doctoral Program, Faculty of Psychology, Gadjah Mada University \\ Directorate of Prevention and Control of Mental Health and Drugs Problems, Ministry of Health RI \\ osikusuma@gmail.com \\ Subandi** \\ Faculty of Psychology, Gadjah Mada University \\ subandi@ugm.ac.id
}

\begin{abstract}
Add psychological interventions based mental health services community for treating people with schizophrenia (ODS) can provide positive opportunities in the recovery process. However, there was no systematic literature review for this yet. This article aims to identify and synthesize ODS's psychological interventions in the community to portray held various interventions. A systematic narrative review with the procedure of PRISMA was used in this research. The inclusion criteria are I) psychological intervention; 2) involvement of a psychologist; 3) community settings. The search was carried out from April- May 2020. Out of 103 journals, 72 journals were reviewed, and a total of 7 journals were analyzed in this study. The involvement of psychologists in crucial positions in community mental health services is rare. Most of the interventions are led by psychiatrists. Psychological interventions include psychoeducation, CBT, SST, social support therapy, and online psychotherapy with "telementalhealth". Psychosocial interventions are given with pharmacotherapy. There was a positive effect of using psychological interventions for ODS in the community. Intervention on ODS in the community must involve multidisciplinary and multi-professional skills. Psychologists' involvement in psychological interventions can improve clinical outcomes and psychological flexibility to provide satisfaction to patients. It supports recovery-oriented mental health services.
\end{abstract}

Keywords: psychological intervention; schizophrenia; psychologist; community

Received 30 April 202I/Accepted I8 August 202I @Author all rights reserved

\section{Introduction}

The proper handling and care for people with schizophrenia (ODS) still need to find the correct pattern to support and complement pharmacotherapy treatment commonly given to patients. A collaboration involving the professions, institutions, and communities is necessary. The majority of ODS treatments are still directed at pharmacotherapy to control positive symptoms in the short term. The development of current treatments requires more comprehensive treatment to reduce negative symptoms. Antipsychotics most effectively reduce psychotic symptoms, and they have 
minimal effects on negative symptoms, cognitive impairment, or function. Meanwhile, psychosocial interventions can provide functional improvements (Harris \& Boyce, 2013; Mueser, Deavers, Penn, \& Cassisi, 2013).

In the last decade or so, the basis of mental health care has changed, from the concept of admission to a specialized mental hospital or mental health rehabilitation centre to community -based care (Whiteford \& Buckingham, 2005). The study conducted by Chatterjee et al. (2014) states that community collaborative-based care plus facility-based care is a little more effective than treatments that rely on formal health facilities. Besides that, the care system's design by paying attention to cultural and community perspectives that involve the caregiver and the patient himself (Subandi, 2012; Subandi, Praptomojati, Marchira, DelVecchio Good, \& Good, 2020) significantly reduces disability and symptoms of psychosis. Thus, it is interesting to involve psychologists in communitybased mental health service interventions because they can provide positive ODS recovery opportunities.

Treatment or interventions conducted by psychologists only be temporary or by necessity, but significant to help alleviate the symptoms that interfere. it is still necessary to develop a specific and standardized psychological intervention guideline (Ikatan Psikolog Klinis Indonesia, 202I; Sadarjoen, 2008)in the handling of ODS to become a professional reference in providing services. Several other countries have developed(National Institute for Health \& Clinical Excellence, 2014; Royal Australian and New Zealand College of Psychiatrist, 2019; Scottish Intercollegiate Guidelines Network, 2013). From the results of a preliminary study by researchers through FGD with psychologists who provide services at the primary mental health care (puskesmas) in D.I. Yogyakarta, the need for mental health service guidelines by psychologists in the community was identified.

There is no systematic literature review related to intervention by psychologists in the treatment of ODS. Previous systematic literature review related to ODS's psychological interventions did not examine their specific implementation in the community (De Leo \& Spathonis, 2003; Gottlieb, Romeo, Penn, Mueser, \& Chiko, 2013; Ventriglio et al., 2020). The study of (Novianty \& Retnowati, 2016) describes psychologists' work in a mental health care community, especially its contribution 
to supporting the government's program in the treatment of mental health in general, but did not specific for schizophrenia case.

This study aimed to conduct a systematic review of psychological interventions in community mental health services for ODS. Various community interventions involving psychologists were identified. The findings of various interventions in this article are expected to be the basis for psychologists' recommended interventions in managing schizophrenia in the community. The mental health care community is defined as an intervention that involves a multi-sector partnership, including community members (e.g., mental health workers) (Castillo et al., 2019).

\section{Method}

The procedure used to perform a systematic literature review is the Preferred Reporting Items for Systematic reviews and meta-analyses (PRISMA). PRISMA demands detailed steps in the selection of articles to be studied. Two main things have must do. First, determine the inclusion and exclusion criteria or (eligibility criteria). Second, researcher carefully selects steps when searching articles in the database that have predetermined (identification and screening). The inclusion and exclusion criterion in this study is shown in Table I.

Table I

Inclusion and Exclusion Criteria

\begin{tabular}{|c|c|c|}
\hline Criteria & Inclusion & Exclusion \\
\hline Participants & People with schizophrenia & other disorder \\
\hline Study Criteria & $\begin{array}{l}\text { Quantitative, } \\
\text { qualitative, experimental, and mix- } \\
\text { methods. }\end{array}$ & $\begin{array}{l}\text { Apart from using the three } \\
\text { techniques for } \\
\text { inclusion. Using meta-analysis } \\
\text { techniques or systematic } \\
\text { review. }\end{array}$ \\
\hline Intervention & $\begin{array}{l}\text { psychological treatment, psychological } \\
\text { intervention, psychotherapy by } \\
\text { psychologist }\end{array}$ & $\begin{array}{l}\text { psychological treatment that } \\
\text { does not involve a } \\
\text { psychologist }\end{array}$ \\
\hline Destination & $\begin{array}{l}\text { Improve treatment results; increase the } \\
\text { ability of patient }\end{array}$ & $\begin{array}{l}\text { Not related to the purpose of } \\
\text { the intervention }\end{array}$ \\
\hline Language & English and Indonesian & $\begin{array}{l}\text { Languages other than English } \\
\text { and Indonesian }\end{array}$ \\
\hline The place & All & \\
\hline Study range & $2010-2020$ & Before 2010 \\
\hline Keywords & $\begin{array}{l}\text { schizophrenia, psychologists, } \\
\text { psychological intervention, } \\
\text { psychotherapy }\end{array}$ & \\
\hline
\end{tabular}


The keywords used as a search in each database are (I) schizophrenia AND psychologist AND community; (2) psychosis AND psychologist AND community. The alternative search used the keywords psychological intervention and psychotherapy. Searches in Indonesian in use keywords "intervensi psikologis schizophrenia" or "intervensi psikososial berbasis masyarakat".

Psychological intervention is defined as any intervention that focuses on psychological and/or social rather than biological factors (e.g., pharmacotherapy). Community intervention is defined as any intervention delivered in a participant's home or another community setting. Interventions carried out exclusively in health facilities or other institutions (hospitals, clinics, outpatient centers, or special care centers) do not fall within the eligibility criteria. The systematic review focused only on participants who included people with schizophrenia or people with psychosis.

The literature search related to psychologists' involvement in treating ODS in the community was carried out through a database subscribed by Gadjah Mada University (UGM) in 2020, including through SAGE Journals, Scopus, Science Direct, Springer Link, and electronic thesis \& dissertation (ETD) from UGM. This search was carried out from April- May 2020. From the results found 103 literatures that contains keywords included. Of this total, 31 kinds of literature are duplicates, leaving $7 \mathrm{l}$ behind for further analysis. 65 articles excluded because they did not explain psychologists' involvement or demonstrated ODS intervention in the community. The search process and systematic review are shown in diagram I. 


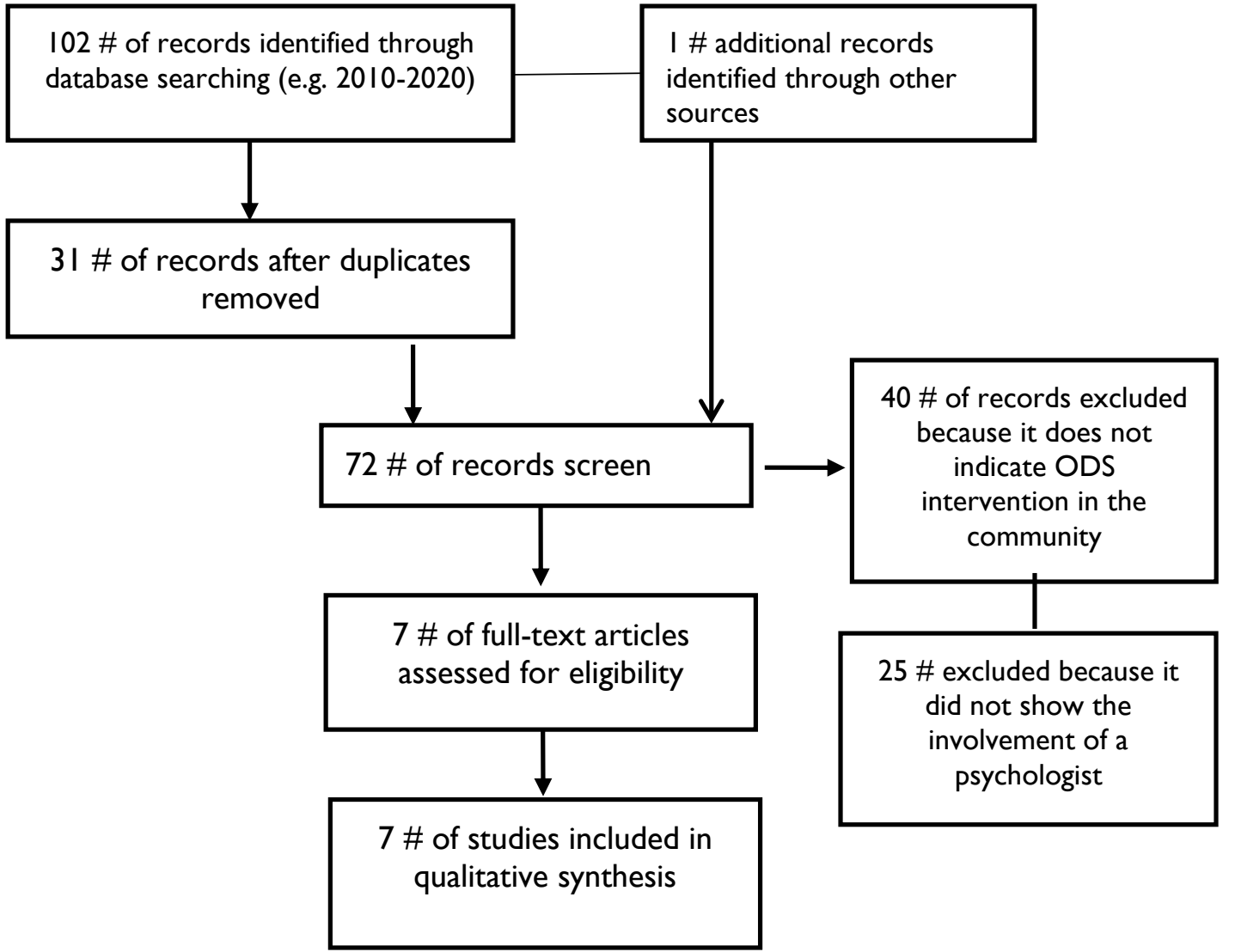

Diagram I. PRISMA flow diagram

A narrative analysis was done to identify the psychologists' roles for the community's ODS intervention from the literature that fits the criteria. Narrative analysis was conducted to present a collection of studies on psychologists' involvement in community mental health services, which have used various methodologies with different intervention models. Narrative analysis is a handy way of connecting many studies with various topics or methods to be reinterpreted to develop or evaluate new ideas, quantitative interpretations and gave empirical evidence (Baumeister \& Hutter, 20I2).

\section{Result}

A summary of the study results according to the eligibility criteria is presented in table 2 . The literature search results show that psychologists' involvement in the ODS intervention in the community cannot stand alone. The entire article demonstrates teamwork involving a psychiatrist, 
mental health nurse, social worker, or mental health service staff. Many interventions are held by psychiatrists who prioritize their maintenance pharmacotherapy equipped with other therapies.

Table 2.

Summary table of the results of the study was included in the eligibility criteria.

\begin{tabular}{cll} 
No. & Author's Name & \multicolumn{1}{c}{ Destination } \\
\hline I & $\begin{array}{l}\text { (Mayer-Amberg, } \\
\text { Woltmann, \& } \\
\text { Walther, 20I6)) }\end{array}$ & $\begin{array}{l}\text { To measure the efficiency of } \\
\text { Integrated Care initiative therapy } \\
\text { involving a multidisciplinary team, } \\
\text { consisting of medical , social , } \\
\end{array}$ \\
& $\begin{array}{l}\text { psychological , and psychotherapy } \\
\text { teams }\end{array}$
\end{tabular}

2 Srihari et al.(2015) to determine the effectiveness of a comprehensive first- episode service, the Clinic for Early N Country Research Design Specialized Treatment in Psychosis (STEP), in a US urban community mental health center by comparing it to usual care .

3 Gucci \& Marmo (2016)

5 Gawęda, Kręzołek, Olbrys̈, Turska, \& Kokoszka(20I5)
To observe how the program is integrated (Institutional Psychiatric Open Light Treatment) for disorders psychos is and personality that is enriched with functions audiovi sual which is provided through the web site specifically to support patients in the lives of everyday them and affect the quality of the process of recovery.

4 Johns et al. (2016) To determine eligibility and acceptance of the ACT group intervention for people with psychosis (G- ACTP).

to assess the impact of training meta- cognitive (MCT) on the bias cognitive, symptoms, insight clinical and functions common in the people who serve the level of the low who was diagnosed with schizophrenia chronic attend Community Social Support Group Program every day.
$7 / 3$ German Descriptive analysis

120

US. Conn

Randomized control ecticut posttest design

446 Italy

Experiment using Pretest-Posttest Group Design

89 London, UK A within-participant pre-post design

44 Poland

Randomized control trial pre and posttest design 
6 Wauchope,

Terlich, \& Lee

(2016) to test the feasibility of the

implementation of "Rel8", group

training skills of social with

models play a role during the 8

weeks were adapted to the

environmental health of mental

community.

7 Setyanto, Hartini, To test effective use of Social

\& Alfian(2017) support to improve independence in patients with schizophrenia

25 Australia Pre and posttest

design

I Indonesia Single case study

A different study was conducted by (Setyanto et al., 2017) with a social support therapy model. In this study, the intervention was carried out solely by a psychologist by involving the patient's family and close friends to provide support. The main target of giving patients intervention is to improve the quality of life through independence by giving independent tasks such as daily living activities. The intervention lasted four weeks. The intervention results showed that the patient was more enthusiastic in doing daily living activities independently because he felt responsible and appreciated. Other intervention models that have been proposed were showed below.

\section{Psychoeducation}

Psychoeducation is the dominant form used by psychologists for community-based ODS interventions. Psychoeducation is carried out side by side with other interventions. Mayer-Amberg et al. (2016) provide psychoeducation alongside sociotherapy, home visits, and family support in an integrated care schizophrenia initiative integrated care program. In this intervention, the emphasis was placed on psychoeducation for patients and families to argue that it is a driving force in community care. Psychoeducation occurs in I full day, with didactic knowledge transfer methods, visualization methods, and interactive conversations. Role plays exercises are a complement to testing theoretical knowledge. From the intervention series made for a median of 18.7 months, the obtained results: the level of satisfaction that is high in care, low readmission rate( $18.4 \%)$, receiving antipsychotic difference within 28 days ( $21.6 \%$ ), low hospitalization patient (6.3\%), the caregiver is involved in the treatment ( $17.1 \%)$, documented suicide rate $(0.4 \%)$; and reduced duration of hospitalization ( $44 \%$ ). 
The study conducted by Srihari et al. (2015) provides psychoeducation interventions to families with a multi-family approach and personal family counselling. Psycho-educational interventions are combined with cognitive behavioural therapy (CBT) and case management for patients and families through the STEP (Specialized Treatment Early in Psychosis) program. Assessment results within six months of the intervention showed an increase in regularity of controls to the hospital and increased vocational ability. However, it is not clear which interventions have the most significant impact on outcomes.

\section{Acceptance and Commitment Therapy (ACT)}

Another intervention has been given through Acceptance and Commitment Therapy (ACT) by Johns et al. (2016). It is designed to increase psychological flexibility (more accepting, more cautious, and a more defused approach) in responding to psychotic symptoms from emotions/thoughts, thereby helping ODS act according to their values. The intervention was given for four weeks with an experiential training workshop model, for example, mindfulness, clarification of personal values, and practical coping training when dealing with relapsing conditions. Patients who received the ACT intervention showed greater acceptance, reduced cognitive fusion, and increased awareness of recurrent symptoms.

Metacognitive tracking (MCT) by Gawęda et al. (20I5) provides psychoeducation to patients to raise awareness of cognitive biases followed by structured and specific cognitive exercises. The intervention gave for four weeks with three module classification models; these are I) psychoeducation (to describe the cognitive bias being targeted and to discuss it with the patient); 2 ) exercise (how certain cognitive biases can be experienced, discuss the consequences of cognitive bias, and provide coping strategies to deal with cognitive bias); and 3) conclusions (to discuss and summarize patient experiences concerning exercise and to discuss how this used in everyday life). There were no significant differences in the implementation of single MCT therapy against the targeted clinical outcomes compared with treatment-as-usual (TAU). However, MCT was found to ameliorate cognitive biases as measured by the self-report scale at large effect size, however, no changes in jumping to conclusions (the Fish Task) and theory of mind deficits ("Reading the Mind in the Eyes" Test) were found in the behavioural tasks. 
Therapy-based application or online

Therapy-based application or online, "app2gether", by Gucci \& Marmo (2016) through telemental health providing conference rooms audio/video to the patient or family through a virtual space that pitch synchronization, according to the scheduled time, and the group is free, or through chat with an asynchronous model for each question or information, being an alternative form of intervention. "App2gther" is designed to complement the Institutional Psychiatric Open Light Treatment (IPOLT) intervention that helps patients reintegrate and reduce stigma. After six months of intervention, the assessment results showed that patients experienced a significant reduction in re-hospitalization and length of stay and improvements in daily function, general function, quality of life, social relationships, and internalization of stigma, and empowerment. This service is an attractive intervention because it can support and monitor patients from where they live. However, proper, simple, and attractive web design modelling and the patient's technological abilities need to be taken into account to make the therapy process right on target.

\section{Social skills training}

Wauchope et al. (2016) offer psychosocial care in community mental health settings to provide recovery-oriented care in ODS. Social skills training (SST) "Rel8", which was given for eight weeks, was improved the patient's belief in doing the role and social skills. This intervention can also increase patient satisfaction because adopting the models plays a role (role plays).

All community-based interventions are intended for outpatient or post-hospital ODS patients. The results of the intervention were seen in the assessment after one month to six months. In this study, there was no specific study to measure the intervention's timing's effectiveness because it to be various. Community-based interventions are not only curative but also promotive, preventive, and rehabilitative. The intervention's primary output leads to improvements in clinical care, such as decreasing chances of relapse or re-treatment in hospital (hospital readmission rate), reduced hospitalization time or possibility, medication adherence, and the presence of the treatment. Meanwhile, secondary output leads to improved psychological and psychosocial flexibility functions, such as managing cognitive bias symptoms, increased social and communication skills, improved daily functioning, community involvement, and reduced stigma. All studies show significant results in improving these secondary outputs. 
Community -based interventions emphasize home-based care and community care centres outside formal hospitals or health institutions. The component that is involved in community intervention is the family. The study conducted by Setyanto et al. (2017) found that social support interventions by family and closest friends were able to increase the patient's sense of independence so that they could carry out personal tasks and daily activities well. Family members and close friends of the patient are involved in discussing the treatment plan and identifying psychosocial stressors that can prevent progress and help as facilitators in implementing the intervention. In other studies, except for the Gaweda study, families or caregivers supported the care model through psychoeducation, CBT, or audio conferences. Families can help patients manage symptoms, reducing the risk of relapse (Mayer-Amberg et al., 2016). However, all studies show an effort to provide opportunities for the choice of care by patients, along with the target intervention outcomes to be achieved (person-centred).

The research design used to test the effectiveness of the intervention for psychotic and schizophrenia is done chiefly experimentally. The random selection of participants from the target population gives strength to the quality of the research on effectiveness testing, which involves two things: scientific quality and ethical quality. In comparison, the design in one article above (Setyanto et al. 2017) is another perspective in proving the effect of intervention in a single case, with specific criteria.

\section{Discussion}

The consequences of assisting ODS in reintegrating into the community put ODS and their families involved in care. Here, a psychological intervention can contribute to improving social, economic, and emotional management skills. Such interventions can also benefit ODS and their families by reducing stigma in the community. It supports the results of a meta-analysis conducted by Asher, Patel, and De Silva (2017) that community-based psychosocial intervention in low-middle-income countries positively affects the management of the severe symptoms of schizophrenia, improved function, and reduce relapse and hospitalization.

De Leo and Spathonis (2003) summarize specific interventions for ODS, either in the personal or community sphere, which include psychosocial elements in the treatment approach, as shown in table 3 . 
Table 3

Psychosocial interventions for schizophrenia patients

\begin{tabular}{ll}
\hline Approach to Treatment & Specific Interventions \\
\hline Case management & Assertive Community Treatment (ACT) \\
Social Skills Training (SST) \\
Vocational rehabilitation \\
Supportive employment \\
Training in community living \\
Cognitive rehabilitation \\
Individual therapy \\
Group therapy \\
Family interventions \\
- Family psychoeducation \\
- Behavioral family management \\
- Behavioral family therapy \\
- Family-aided ACT \\
Social therapy \\
Personal therapy \\
Cognitive behavioral therapy \\
Critically timed interventions \\
Hospitalization \\
Crisis services \\
- Walk-in intervention services \\
- Mobile crisis outreach services \\
- Community residential services \\
- Partial hospitalization programs \\
Family interventions \\
- Family psychoeducation \\
- Behavioral family management \\
- $\quad$ Behavioral family therapy \\
\end{tabular}

Using psychosocial interventions that involve the social context, in this case, shows that it can increase patient commitment to care. Pharmacotherapy can also facilitate commitment and involvement in interventions, thereby increasing psychosocial interventions' benefits (De Leo \& Spathonis, 2003; Kim, Mueser, Deavers, Penn, \& Cassisi, 2013). Things that need to be considered and further studies related to antipsychotics are the possible adverse effects in long-term use.

In Italy, mental health care is more towards community-based care, with pharmacotherapy considered an alternative (Amaddeo, Barbui, \& Tansella, 20I2). The results of a meta-analysis study 
of Álvarez-Jiménez, Parker, Hetrick, McGorry and Gleeson et al. (20II) found that $20 \%$ of FEP ( first episode psychotic) patients did not experience a relapse even though their antipsychotic treatment was stopped. The discontinuation strategy consists of a dose-guided reduction of symptoms gradually, and where possible, restoration of antipsychotic treatment when early detection of relapse occurs. However, the effectiveness of discontinuation strategies in combination with intensive psychosocial care in the community still needs further investigation.

The use of technology in community intervention is an alternative step in helping the recovery of ODS. A systematic review study by Kasckow et al. (2014) concluded that treatment using a telephone, internet, and video conferencing (telepsychiatry) could improve treatment outcomes, including patient-staff communication and medication adherence increased insight, psychopathological symptoms, and home visits. Emergency department, and hospitalization rates in patients with schizophrenia. Mohr, Parker, Hetrick, McGorry and Gleeson (2006) said that practical obstacles in providing health services could be overcome with a telemental health program as an opportunity for psychologist services that can be applied in Indonesia(Sari, Ramdhani, \& Subandi, 2020). Technology-based interventions with appropriate procedures are considered suitable for areas that are difficult to reach because of limited transportation and the very high stigma against mental health services (Tutty, Ludman, and Simon, 2005).

Several models of a community intervention for ODS that include psychosocial elements have been mentioned above. The importance of pharmacotherapy as the primary intervention accompanied by psychological and psychosocial interventions can further improve treatment success by reducing stress, increasing coping skills, reducing the risk of relapse, and increasing medication adherence. A review of various international guidelines by (Ventriglio et al., 2020) suggests that psychosocial interventions in schizophrenia can be helpful in combination with psychopharmacotherapy and psychotherapy. All of these interventions can address the unmet need for the treatment of psychosis and, in particular, enhance the psychosocial functioning of patients to enhance their longterm recovery from the disease. In particular, negative symptoms and private functions (including social, work, and cognitive).

To achieve that the teamwork by clinical psychologists, psychiatrists, nurses, and general practitioners is needed. It can support psychoeducation as a significant part of the intervention to address information gaps for caregivers, patients, and the environment Jacobs, Kline, \& Schiffman, 
2012; Marchira, Puspitosari, Rochmawati, Mulyani, \& Supriyanto, 2018) and assist in a comprehensive treatment rather than being limited to an assessment given by a general practitioner. Likewise, in Indonesia, community care provided at puskesmas requires a psychologist's involvement to help provide psychoeducation and manage the stigma about mental disorders (Setiyawati, Blashki, Wraith, Colucci, \& Minas, 2014), supporting psychosocial interventions' success. Of course, this requires community support and involvement (Kurniawan \& Sulistyarini, 2017). More resources can be allocated to provide full-scale psychosocial interventions are recommended.

\section{Recomendation}

The main objective of this study is to conduct a systematic review of psychological interventions in community mental health services for people with schizophrenia, involving psychologists in their management. The findings of this study can underlie further research on the role of professional psychologists in mental health services in Indonesia. It would be advantageous if further exploration were carried out through a survey with a broader sample to obtain a more comprehensive study of the available psychological services. Developing a psychological service system in community health is another research domain that has the opportunity to be carried out. Mapping of psychological services by the existing health care system and evaluating the provision of psychological services in mental health efforts in the community in the Indonesian system can be another critical area of research.

\section{Conclusion}

Various psychological interventions for ODS in the community have been carried out, including psychoeducation, Cognitive Behavioural Therapy (CBT), social skill training (SST), social support interventions, and psychological intervention with telemental health. Psychological intervention not only has an impact on improving clinical outcomes but also psychological flexibility. All interventions given show a combination with pharmacotherapy; therefore, the ODS care team is often led by a psychiatrist involving psychologists and other health professionals such as doctors and nurses. The effectiveness of the type of psychological therapy provided within the health centre needs to be further investigated. Likewise, allowing patients to choose their treatment as required indicates recovery-oriented practices. 


\section{Research Limitations}

This review aims to find an overview of the various psychological interventions carried out in community settings. We do not limit it to specific interventions but map out what can be done. So, of course, increased heterogeneity, especially regarding the effectiveness, time, or the design of the implementation, limits the possibility to draw clear conclusions or to combine the results statistically. However, this research can serve as a background for further research in integrating psychological services into the health care system in the community..

\section{References}

Álvarez-Jiménez, M., Parker, A. G., Hetrick, S. E., McGorry, P. D., \& Gleeson, J. F. (20II). Preventing the second episode: A systematic review and meta-analysis of psychosocial and pharmacological trials in first-episode psychosis. Schizophrenia Bulletin, 37(3), 619-630. https://doi.org//0.1093/schbul/sbp 129

Amaddeo, F., Barbui, C., \& Tansella, M. (2012). State of psychiatry in Italy 35 years after psychiatric reform. A critical appraisal of national and local data. International Review of Psychiatry, 24(4), 3|4-320. https://doi.org/I0.3 I09/0954026I.2012.694855

Asher, L., Patel, V., \& De Silva, M. J. (2017). Community-based psychosocial interventions for people with schizophrenia in low and middle-income countries: Systematic review and meta-analysis. BMC Psychiatry, I7(I), I-I5. https://doi.org/I0.II86/s I2888-0I7-I5I6-7

Baumeister, H., \& Hutter, N. (2012). Collaborative care for depression in medically ill patients. Current Opinion in Psychiatry, 25(5), 405-4I4. https://doi.org/I 0. I097/YCO.0b0 I 3e3283556c63

Castillo, E. G., ljadi-Maghsoodi, R., Shadravan, S., Moore, E., Mensah, M. O., Docherty, M., ... Wells, K. B. (2019). Community Interventions to Promote Mental Health and Social Equity. Current Psychiatry Reports, 2 I(5). https://doi.org/10.1007/s I 1920-019-1017-0

Chatterjee, S., Naik, S., John, S., Dabholkar, H., Balaji, M., Koschorke, M., ... Thornicroft, G. (20I4). Effectiveness of a community-based intervention for people with schizophrenia and their caregivers in India (COPSI): A randomised controlled trial. The Lancet, 383(9926), 1385-1394. https://doi.org/I0.1016/S0140-6736(I3)62629-X

De Leo, D., \& Spathonis, K. (2003). Do psychosocial and pharmacological interventions reduce suicide in schizophrenia and schizophrenia spectrum disorders? Archives of Suicide Research, 7(4), 353-374. https://doi.org//0.1080/7/3848945

Gawęda, Ł., Kręzołek, M., Olbrys̈, J., Turska, A., \& Kokoszka, A. (20I5). Decreasing self-reported cognitive biases and increasing clinical insight through meta-cognitive training in patients with chronic schizophrenia. Journal of Behavior Therapy and Experimental Psychiatry, 48, 98-104. https://doi.org/10.1016/j.jbtep.2015.02.002

Gottlieb, J. D., Romeo, K. H., Penn, D. L., Mueser, K. T., \& Chiko, B. P. (2013). Web-based cognitive-behavioral therapy for auditory hallucinations in persons with psychosis: A pilot 
study. Schizophrenia Research, I45(I-3), 82-87. https://doi.org/I0.1016/j.schres.2013.0I.002

Gucci, F., \& Marmo, F. (2016). A study on the effectiveness of E-Mental Health in the treatment of psychosis: Looking to recovery. European Psychiatry, 33(SI), S27-S28. https://doi.org/10.1016/j.eurpsy.2016.01.846

Harris, A., \& Boyce, P. (20I3). Why do we not use psychosocial interventions in the treatment of schizophrenia? Australian and New Zealand Journal of Psychiatry, 47(6), 50I-504. https://doi.org/10.1I77/0004867413489173

Ikatan Psikolog Klinis Indonesia. (202I). Pedoman nasional pelayanan psikolog klinis. Yogyakarta: Ikatan Psikolog Klinis Indonesia.

Jacobs, E., Kline, E., \& Schiffman, J. (2012). Defining treatment as usual for attenuated psychosis syndrome: A survey of community practitioners. Psychiatric Services, 63(12), 1252-1256. https://doi.org/I0.I I76/appi.ps.20I 200045

Johns, L. C., Oliver, J. E., Khondoker, M., Byrne, M., Jolley, S., Wykes, T., ... Morris, E. M. J. (20I6). The feasibility and acceptability of a brief Acceptance and Commitment Therapy (ACT) group intervention for people with psychosis: The "ACT for life" study. Journal of Behavior Therapy and Experimental Psychiatry, 50, 257-263. https://doi.org/10.1016/j.jbtep.2015.10.00I

Kasckow, J., Felmet, K., Appelt, C., Thompson, R., Rotondi, A., \& Haas, G. (20I4). Telepsychiatry in the assessment and treatment of schizophrenia. Clinical Schizophrenia and Related Psychoses, 8(I). https://doi.org/I0.337I/CSRP.KAFE.0215I3

Kurniawan, Y., \& Sulistyarini, I. (2017). Komunitas sehati (Sehat Jiwa dan Hati) sebagai intervensi kesehatan mental berbasis masyarakat. INSAN Jurnal Psikologi Dan Kesehatan Mental, I (2), II 2. https://doi.org/I0.20473/jpkm.vli22016.II2-124

Marchira, C. R., Puspitosari, W. A., Rochmawati, I., Mulyani, S., \& Supriyanto, I. (20I8). Managing information gaps on caregivers of psychotic patients in primary health settings of Yogyakarta, Indonesia. Health Promotion Perspectives, 8(2), I63-166. https://doi.org/10.1517//hpp.2018.21

Mayer-Amberg, N., Woltmann, R., \& Walther, S. (2016). An integrated care initiative to improve patient outcome in schizophrenia. Frontiers in Psychiatry, 6(JAN), I-7. https://doi.org// 0.3389/fpsyt.2015.00184

Mohr, D. C., Hart, S. L., Howard, I., Julian, L., Vella, L., Catledge, C., \& Feldman, M. D. (2006). Barriers to psychotherapy among depressed and nondepressed primary care patients. Annals of Behavioral Medicine, 32(3), 254-258.

Mueser, K T, Deavers, F., Penn, D. L., \& Cassisi, J. E. (20/3). Psychosocial treatments for schizophrenia. Annual Review of Clinical Psychology, Vol. 9, pp. 465-497. https://doi.org/I0.1 I46/annurev-clinpsy-0502 I2-185620

Mueser, Kim T., Deavers, F., Penn, D. L., \& Cassisi, J. E. (2013). Psychosocial treatments for schizophrenia. Annual Review of Clinical Psychology, 9(1), 465-497. https://doi.org/ I0.I |46/annurev-clinpsy-0502 I2-185620

National Institute for Health \& Clinical Excellence. (2014). Schizophrenia. Core interventions in the treatment and management of schizophrenia in adults in primary and secondary care.

Novianty, A., \& Retnowati, S. (2016). Intervensi Psikologi di layanan kesehatan primer. Buletin 
Psikologi, 24(I), 49. https://doi.org/I0.22 I46/bpsi. I 2679

Royal Australian and New Zealand College of Psychiatrist. (2019). Guidelines on schizophrenia: A synopsis by Prof Castle.

Sadarjoen, S. (2008). Standar pelayanan psikologi klinis (SPPK). Himpunan Psikologi Indonesia (HIMPSI).

Sari, O. K., Ramdhani, N., \& Subandi, M. A. (2020). Kesehatan mental di era digital: Peluang pengembangan layanan profesional psikolog. Media Penelitian Dan Pengembangan Kesehatan, 3(4), 337-348. https://doi.org/DOI: https://doi.org/ I0.22435/mpk.v30i4.33 I I

Scottish Intercollegiate Guidelines Network. (20I3). . Management of schizophrenia.

Setiyawati, D., Blashki, G., Wraith, R., Colucci, E., \& Minas, H. (20I4). Indonesian experts' perspectives on a curriculum for psychologists working in primary health care in Indonesia. Health Psychology and Behavioral Medicine. https://doi.org/I0.1080/21642850.2014.912946

Setyanto, A. T., Hartini, N., \& Alfian, I. N. (2017). Penerapan social support untuk meningkatkan kemandirian pada penderita skizofrenia. Jurnal Wacana Psikologi, 9(I), 9I-II5.

Srihari, V. H., Tek, C., Kucukgoncu, S., Phutane, V. H., Breitborde, N. J. K., Pollard, J., ... Woods, S. W. (20I5). First-episode services for psychotic disorders in the U.S. public sector: A pragmatic randomized controlled trial. Psychiatric Services, 66(7), 705-712. https://doi.org/I0.I I76/appi.ps.201400236

Subandi, M. A. (2012). Agama dalam perjalanan gangguan mental psikotik dalam konteks budaya Jawa. Jurnal Psikologi, 39(2), 167-179.

Subandi, M. A., Praptomojati, A., Marchira, C. R., DelVecchio Good, M. J., \& Good, B. J. (2020). Cultural explanations of psychotic illness and care-seeking of family caregivers in Java, Indonesia. Transcultural Psychiatry. https://doi.org/10.1 I77//3634615209/6290

Tutty, S., Ludman, E. J., \& Simon, G. (2005). Feasibility and acceptability of a telephone psychotherapy program for depressed adults treated in primary care. General Hospital Psychiatry, 27(6), 400-4I0. https://doi.org/I0.1016/j.genhosppsych.2005.06.009

Ventriglio, A., Ricci, F., Magnifico, G., Chumakov, E., Torales, J., Watson, C., ... Bellomo, A. (2020). Psychosocial interventions in schizophrenia: Focus on guidelines. International Journal of Social Psychiatry, 66(8), 735-747. https://doi.org//0.1 I77/0020764020934827

Wauchope, B., Terlich, A., \& Lee, S. (2016). Rel8: Demonstrating the feasibility of delivering an 8week social skills program in a public mental health setting. Australasian Psychiatry, 24(3), 285288. https://doi.org// 0.1 I77//0398562/56/2992

Whiteford, H. A., \& Buckingham, W. J. (2005). Ten years of mental health service reform in Australia: Are we getting it right? Medical Journal of Australia, I82(8), 396-400. https://doi.org// 0.5694/j.1326-5377.2005.tb06758.x 